\title{
Effects of water stress at different growth stages on comprehensive fruit quality and yield in different bunches of tomatoes in greenhouses
}

\author{
Shuxue Hao, Hongxia Cao*, Hubing Wang, Xiaoyan Pan \\ (Key Laboratory of Agricultural Soil and Water Engineering in Arid and Semiarid Areas, Ministry of Education, \\ Northwest A \& F University, Yangling 712100, China)
}

\begin{abstract}
The aim of this study was to investigate the effects of tomato quality and yield between different bunches and the differences between the two comprehensive evaluation methods on tomato quality ranking under water stress. Two degrees of water stress including mild water stress (W1) and moderate water stress (W2), and three growth stages that water stress applied including seedling stage (S1), flowering stage (S2) and fruit expanding stage (S3) were tested in this study. The yield and quality of different bunches of tomatoes under water stress during different growth stages were determined as responses, and the comprehensive fruit quality ranking and yield of the second and third bunches were evaluated. The results showed that water stress was important for the improvement of fruit quality, but fruit yield decreased during water stress. The yield of the third tomato bunch decreased from $11.69 \%$ (W1S1) to $30.60 \%$ (W2S2) compared to control $\left(97.57 \mathrm{t} / \mathrm{hm}^{2}\right.$ ), and the effects of mild water stress on fruit yield were minimal at the early growth stage. However, the fruit quality in terms of soluble sugar (SS), total soluble solids (TSS), vitamin C (VC), and firmness (F) improved under water stress compared to control. The combined effects of water stress and its application period significantly affected SS and TSS. Water stress significantly improved the content of SS and TSS in the later growth period compared to seedling and flowering stages. Meanwhile, there was a significant difference in tomato quality between the second and third bunches of fruit, especially in the content of SS, organic acid (OA) and lycopene (L). Principal Component Analysis (PCA) and Grey Relational Analysis (GRA) were used to evaluate comprehensive fruit quality, and the best treatment in terms of the fruit quality was W1S3 for both bunches. The rank-sum ratio (RSR) method was used to evaluate fruit quality and yield, the results showed that W1S3 ranked first based on PCA and W1S1 ranked first based on GRA. Water stress enhanced tomato quality but inevitably reduced its yield during each growth stage. The application of mild water stress during the fruit expanding stage (W1S3) was considered to be the best treatment to provide satisfactory fruit quality and yield based on RSR.
\end{abstract}

Keywords: water stress, growth stages, tomato, comprehensive fruit quality, yield, greenhouse

DOI: $10.25165 /$ j.ijabe.20191203.4468

Citation: Hao S X, Cao H X, Wang H B, Pan X Y. Effects of water stress at different growth stages on comprehensive fruit quality and yield in different bunches of tomatoes in greenhouses. Int J Agric \& Biol Eng, 2019; 12(3): 67-76.

\section{Introduction}

Tomato (Solanum lycopersicum L.) is one of the most consumed vegetable crops throughout the world ${ }^{[1,2]}$. Tomato contains minerals, vitamins, polyphenol, and lycopene, which have health benefits for human beings. Lycopene is a type of natural antioxidant that protects lipids, protein, and DNA in cells from free radical oxidative damage ${ }^{[3,4]}$. With the improvement of people's life quality in China, the demand for tomato quality is constantly increasing ${ }^{[5]}$. However, its growth period is a bit longer than other vegetables, and tomato is extremely susceptible to water stress. In addition, soil moisture requirement varies among growth stages of tomato ${ }^{[6,7]}$. Adequate irrigation might lead to a high yield, but the maximum yield typically does not result in a better financial return due to the low price and fruit quality of tomato. In addition, water resources are scarce in

Received date: 2018-06-13 Accepted date: 2019-03-25

Biographies: Shuxue Hao, Master, research interest: agricultural water-saving irrigation, E-mail: haoshuxue925@163.com; Hubing Wang, Master, research interest: agricultural water-saving irrigation, E-mail: whbing660088@163.com; Xiaoyan Pan, Master, research interest: agricultural water-saving irrigation, E-mail: 2865779610@qq.com.

*Corresponding author: Hongxia Cao, PhD, Professor, research interest: agricultural water-saving irrigation, College of Water Resources and Architectural Engineering, Northwest A \& F University, No. 22 Xinong Rd, Yangling 712100, Shaanxi, China. Tel: +86-18192901021, Email: nschx225@nwafu.edu.cn. northwest China due to the lack of sustainable agricultural development. Unreasonable irrigation will not improve the fruit quality, but reduce the water use efficiency. Increasing consciousness regarding reducing water usage in agriculture is necessary for agricultural sustainability ${ }^{[8]}$. Therefore, meeting the water requirements of tomato is crucial for conserving agricultural water resources and increasing water use efficiency along with high quality production of tomato ${ }^{[9]}$.

Fruit quality depends on several indicators, i.e. vitamin C (VC), lycopene (L), soluble sugar (SS), total soluble solids (TSS) and fruit shape, and they change with water and environment stress ${ }^{[10]}$. El Jaouhari et al. ${ }^{[1]}$ indicated that the firmness and total soluble solids of apple under deficit irrigation increased significantly compared to control. Conesa et al. ${ }^{[12]}$ found that deficit irrigation at harvest would improve fruit quality of watermelon, hot pepper and tomato due to increased total soluble solids and juice proline content. Furthermore, the deficit irrigation can significantly reduce the titratable acid content of peach fruit ${ }^{[13]}$, and increased irrigation can significantly reduce the VC, lycopene and SS content of tomato ${ }^{[14]}$. Previous research has focused on the effects of water stress on tomatoes ${ }^{[15,16]}$, but no studies have been conducted on the effects of water stress on different tomato bunches. Fruit quality of different bunches is expected to vary, but it is not clear whether the variation between different fruit bunches is significant. Therefore, it is necessary to study the differences in fruit quality 
between different bunches of tomato under water stress at different growth stages.

At present, there are many methods for evaluating the overall quality of fruit such as cluster analysis, principal component analysis (PCA), multi-dimensional value theory, fuzzy matrix method and grey relational analysis (GRA) ${ }^{[17]}$. Fruit quality is a comprehensive system that can be classified in several aspects including external appearance, flavor, and nutritional and storage quality. These indicators are complex, and it is difficult to distinguish the order of all variables. Original data composed of multiple associated quality variables can be reduced to two or three factors for which linear combinations of source data can accurately identify the majority of the variances using $\mathrm{PCA}^{[18-20]}$. PCA is an effective method based on studies evaluating the comprehensive quality of tomato, bayberry, apple, kiwi fruit, sweet cherry, and soybean $^{[21-27]}$. GRA is a method used to determine the main factors and the degree of correlation of grey systems and is different from other traditional statistical analyses ${ }^{[28]}$. These two methods were selected in this study for the evaluation of tomato fruit quality. After the best comprehensive quality had been achieved, tomato quality and yield are considered as a whole to determine the overall ranking through the rank-sum ratio method (RSR). RSR is a comprehensive evaluation method that integrated parametric and non-parametric statistical methods ${ }^{[29]}$. It can help to evaluate the comprehensive quality and yield of different bunches that haven't been illustrated by other studies.

There are many studies concerning the response of tomato quality and yield to water stress, and tomato yield and quality to water stress in different growth periods were need to be determined. Therefore, the objectives of this study were: (1) to explore the differences in fruit quality and yield of each tomato fruit bunch in response to water stress in different growth periods; (2) to evaluate the comprehensive quality and yield using PCA, GRA and RSR, and determine whether the quality analysis is reasonable with only one bunch of fruit; and (3) to determine the suitable timing and degree of deficit irrigation of tomatoes grown in a greenhouse.

\section{Materials and methods}

\subsection{Experimental site and materials}

This experiment was conducted in the greenhouse of the Key Laboratory of Agricultural Soil and Water Engineering in Arid and Semiarid Areas of the Ministry of Education at the Northwest Agriculture \& Forestry University, Shaanxi, China (latitude $34^{\circ} 18^{\prime} \mathrm{N}$, longitude $108^{\circ} 40^{\prime} \mathrm{E}$, altitude $521 \mathrm{~m}$ ) from February to June 2017. The tomato seeds were sown on December 29, 2016, tomato plants were transplanted at the four-leaf stage on February 18, 2017. The second and third bunches of fruit were harvested on June 4 and June 15, 2017. The area of this greenhouse is $36 \mathrm{~m}$ $\times 10.3 \mathrm{~m}$, and the actual experimental area was $12 \mathrm{~m} \times 9 \mathrm{~m}$. The perennial average temperature is $14.5^{\circ} \mathrm{C}$, and annual average precipitation is $630 \mathrm{~mm}$. The site has a typical temperate continental monsoon climate along with annual sunshine duration of $1900 \mathrm{~h}$ and annual evaporation in the range of 900-1100 mm. The variety of tomato used for the experiment was "Jinpengmeilin" and when the experiment was concluded, there were four bunches of fruit for each tomato plant. The test soil was clay loam, which was taken from the $0-20 \mathrm{~cm}$ surface layer of top soil at the nearby Northwest Agriculture \& Forestry University. The soil bulk density was $1.3 \mathrm{~g} / \mathrm{cm}^{3}$ and the field capacity was $31.3 \%$ (volumetric moisture content), the wilting point moisture content was $8.8 \%$. The experimental soil has the organic matter of $6.18 \mathrm{~g} / \mathrm{kg}$, total nitrogen of $0.84 \mathrm{~g} / \mathrm{kg}$, total phosphorus of $0.45 \mathrm{~g} / \mathrm{kg}$, total potassium of $13.6 \mathrm{~g} / \mathrm{kg}$, available nitrogen of $10.9 \mathrm{mg} / \mathrm{kg}$, available phosphorus of $4.19 \mathrm{mg} / \mathrm{kg}$, and the available potassium of $101.6 \mathrm{mg} / \mathrm{kg}$. The basic climate information of the site is listed in Table 1.

Table 1 Basic climate information of study site throughout the experimental periods

\begin{tabular}{cccccc}
\hline Time & $T_{\max } /{ }^{\circ} \mathrm{C}$ & $T_{\min } /{ }^{\circ} \mathrm{C}$ & $T_{\text {mean }} /{ }^{\circ} \mathrm{C}$ & $R H_{\text {mean }} / \%$ & $\mathrm{SR} / \mathrm{W} \cdot \mathrm{m}^{-2}$ \\
\hline Feb & 40.5 & -3.9 & 11.7 & 60.77 & 24.16 \\
Mar & 41.5 & 3.9 & 15.1 & 61.04 & 25.85 \\
Apr & 41.9 & 8.6 & 21.6 & 61.40 & 38.99 \\
May & 42.4 & 9.8 & 21.2 & 58.81 & 42.70 \\
Jun & 43.8 & 15.9 & 26.1 & 59.73 & 49.92 \\
\hline
\end{tabular}

Note: $T_{\max }, T_{\min }$ and $T_{\text {mean }}$ were the maximum, minimum and average temperature of each month. $R H$ means the relative humidity of the greenhouse, and SR means the solar radiation of the greenhouse.

\subsection{Experimental design}

After $1 \mathrm{~kg}$ river sand was put into the plastic pot with mouth diameter of $30 \mathrm{~cm}$, bottom diameter of $25 \mathrm{~cm}$ and a height of $30 \mathrm{~cm}$, the $15 \mathrm{~kg}$ air-dried soil was placed in it. Seven holes $(5 \mathrm{~mm}$ diameter) were drilled on the bottom of the pot, and a plastic plate was put under the pot to prevent water loss. Two PVC tubes were inserted vertically into the bottom of each pot and three rows of round holes were drilled for watering (Figure 1). Tomato plants were transplanted at the four-leaf stage on February 18, 2017 and uprooted on June 18, 2017. A completely randomized design was arranged for the potted experiment with three replications. There were 210 pots in total with two factors including water stress and different growth stages.

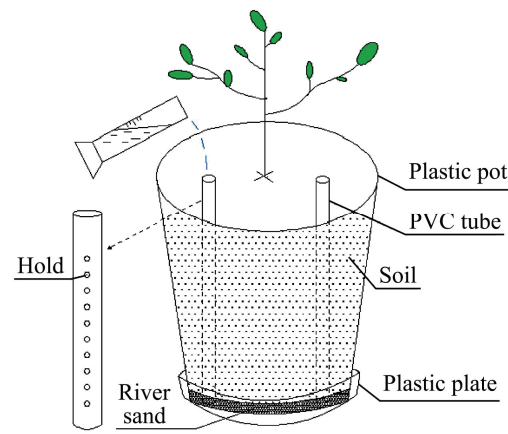

Figure 1 Arrangement of each pot in the experiment

The degree of water stress was determined based on the soil moisture content. Two levels of water stress were set up including mild water stress (W1) and moderate water stress (W2), in which the soil moisture content was $50 \%-60 \%$ and $40 \%-50 \%$ of field capacity, respectively. The control treatment (WS), had soil moisture content of $70 \%-80 \%$ of field capacity during all growth stages. The irrigation amount of different treatments was determined according to a preliminary experiment. The stress treatment continued for $18 \mathrm{~d}$ during each growth stage: seedling stage (S1), flowering stage (S2) and fruit expanding stage (S3). After the water stress was completed, all tomato plants under different treatments were irrigated to $70 \%-80 \%$ of field capacity. Irrigation was applied using the weighing method when the soil moisture content reached the lower limit, provided at 8:00 am and 8:00 pm every day. The tomato plants were firstly fertilized before planting, then fertilized at the first and second fruit expanding stage. The same amount of fertilizer was applied three times, contained $3.18 \mathrm{~g}$ urea $(\mathrm{N})$ which was equivalent to $240 \mathrm{~kg} / \mathrm{hm}^{2}$ of nitrogen, $1.81 \mathrm{~g}$ potassium sulfate $(\mathrm{K})$ which was equivalent to $150 \mathrm{~kg} / \mathrm{hm}^{2}$ of potassium and $4.62 \mathrm{~g}$ enzyme- activated phosphate fertilizer (P) which was equivalent to $120 \mathrm{~kg} / \mathrm{hm}^{2}$ of phosphorus 
per pot. Pests and weeds were controlled according to local practices.

\subsection{Measurement parameters and methods}

\subsubsection{Fruit quality parameters}

Six fruits with the same maturity and size were picked from the second and third bunches of tomato for fruit quality measurements. Three fruits were used to measure the diameter, fruit firmness (F), fruit shape index (FSI) and fruit color index (FCI). The other three fruits were put in a blender and juiced to measure nutrient and taste quality. The fruit firmness was measured by a fruit firmness tester (FRH-5). The fruit shape index is the ratio of fruit longitudinal diameter and transverse diameter of the selected tomatoes. The FSI was calculated as:

$$
F S I=\frac{y}{x}
$$

where, FSI represents the fruit shape index; $y$ is the maximum fruit longitudinal diameter; and $x$ is the maximum value of the fruit transverse diameter.

The fruit color index was measured using a portable colorimeter. The FSI was determined using a portable colorimeter to measure the fruit body and fruit shoulder three times. Three values of color space coordinates - L, a, and b - were expressed from four fruit equatorial orientations. The formula of fruit color index constructed by $\mathrm{L}, \mathrm{a}$, and $\mathrm{b}$ was ${ }^{[30]}$ :

$$
F C I=2000 \times \frac{a}{L \sqrt{\left(a^{2}+b^{2}\right)}}
$$

where, $F C I$ is the fruit color index; a is a scale ranging from -100 (green) to +100 (red), where $a=0$ is gray; $L$ is the lightness ranging from 0 (black) to 100 (white); and $b$ is a scale ranging from -100 (blue) to +100 (yellow), where $b=0$ is gray.

TSS was determined with a handheld saccharometer (IR200S, Shanghai, China). SS was measured using the anthrone colorimetric method. VC was measured using the ammonium molybdate colorimetric method. Organic acid (OA) was titrated with $0.1 \mathrm{~mol} / \mathrm{L}$. Ultraviolet-visible spectrophotometry was used for measuring lycopene (EV300PC, Thermo Fisher, USA). The overall quality of the two bunches was based on the average values of the second and the third bunches of fruits.

\subsubsection{Fruit yield parameters}

The mature fruits of the second and third bunch were weighed with an electronic balance to measure the yield of each spike. The overall yield of the two bunches was calculated from the average values of the second and third bunch of fruits.

\subsection{Comprehensive quality evaluation methods}

\subsubsection{Principal Component Analysis (PCA)}

PCA is the study of interpreting the majority of the original variables using a few linear combinations of the initial data. The factor loading matrix and eigenvalue of components are obtained by PCA. The extraction principle of PCA is that the corresponding eigenvalue should be greater than one. The mathematical model of PCA is as follows:

First of all, raw data is standardized using the $Z$-score method

$$
x *=\frac{x-\mu}{\sigma}
$$

where, $\mu$ is the average value of raw data and $\sigma$ is the standard deviation of raw data.

$$
\left\{\begin{array}{l}
Y_{1}=u_{11} X_{1}+u_{12} X_{2}+\ldots+u_{1 p} X_{p} \\
Y_{2}=u_{21} X_{1}+u_{22} X_{2}+\ldots+u_{2 p} X_{p} \\
\mathrm{M} \\
Y_{P}=u_{P 1} X_{1}+u_{P 2} X_{2}+\ldots+u_{P p} X_{p}
\end{array}\right.
$$

It could be represented as the matrix

$$
Y=U X
$$

where, $X=\left(X_{1}, X_{2}, \ldots, X_{P}\right)^{\prime}$ represents a random vector.

$$
\text { The cumulative variance contribution }=\sum_{k=1}^{m} \lambda_{k} / \sum_{i=1}^{p} \lambda_{i}
$$

where, $\lambda$ is the corresponding eigenvalue for each principal component; $k$ is the principal component selected, and $i$ is the total number of principal components.

\subsubsection{Grey Relational Analysis (GRA)}

GRA was calculated in Microsoft Excel 2010 (Microsoft, USA). The quality indicators were considered a grey system, and each quality variable was regarded as a factor. The similarity of the geometry of the curve was used to judge the correlation. $G_{0}$ was set as the reference vector and the grey correlation of the sample and reference vector were calculated according to the following formula ${ }^{[31]}$ :

$$
\gamma_{i j}=\frac{\min _{n} \min _{m}\left|b_{0 j}-b_{i j}\right|+\rho \max _{n} \max _{m}\left|b_{0 j}-b_{i j}\right|}{\left|b_{0 j}-b_{i j}\right|+\rho \max _{n} \max _{m}\left|b_{0 j}-b_{i j}\right|}
$$

where, $\gamma_{i j}$ is the correlation coefficient of the $j$ th index of the $i$ th sample; $\left|b_{0 j}-b_{i j}\right|$ is the absolute difference between the sample and the reference vector; $\min _{n} \min _{m}\left|b_{0 j}-b_{i j}\right|, \max _{n} \max _{m}\left|b_{0 j}-b_{i j}\right|$ are the minimum and maximum absolute differences of the two levels; and $\rho$ is the distinguishing coefficient.

The formula for calculating the weighted correlation between each evaluation object is:

$$
\gamma_{i}=\sum_{j=1}^{m} w_{j} \gamma_{i j}
$$

where, $\gamma_{i}$ is the weighted correlation, and $w_{j}$ is the index weight; the weight of each index is the contribution of the common factor variance to the overall variation in PCA.

2.4.3 Method of calculating the comprehensive quality rank

The Spearman rank correlation was used to test the correlation between PCA and GRA rankings. The Spearman rank correlation coefficient is usually considered a permutation of the Pearson correlation coefficient between the variables. However, there is a simpler way to calculate the Spearman correlation coefficient. Assuming that $x_{i}, y_{i}$ are in order from large to small, then note $x_{i}{ }^{\prime}$, $y_{i}{ }^{\prime}$ as the location of the $x_{i}, y_{i}$ in the permutation, and $x_{i}{ }^{\prime}, y_{i}{ }^{\prime}$ are called the rank of $x_{i}, y_{i}$. The Spearman correlation coefficient was calculated using the following formula ${ }^{[32]}$.

$$
\rho_{s}=1-\frac{6 \sum_{i=1}^{n} d_{1}^{2}}{n\left(n^{2}-1\right)}
$$

where, $\rho_{s}$ is the Spearman correlation coefficient; $d_{i}$ is the difference value of $x_{i}{ }^{\prime}, y_{i}{ }^{\prime}$, and $n$ is the number of samples.

2.4.4 Comprehensive evaluation of tomato yield and quality using the rank-sum ratio method (RSR)

The rank-sum ratio method (RSR) was used to address comprehensive evaluation of multiple indicators. First the rank of each evaluation index was sorted. Then, the weighted rank-sum ratio (wRSR) was calculated with standardized data:

$$
\begin{gathered}
y_{i j}=w_{j} \frac{x_{i j}}{\sqrt{\sum_{i=1}^{7} x_{i j}^{2}}} \\
{\mathrm{w} R S R_{i}}=\frac{1}{n} \cdot \sum_{j=1}^{m} w_{j} R_{i j}
\end{gathered}
$$


where, $n$ is the evaluation object; $w_{j}$ is the weight of the $j$ th evaluation index, and $R_{i j}$ is the ranking of the $j$ th column element in the $i$ th row.

The index weight was determined using the coefficient of variation method. The weight was calculated using the following formulas:

$$
\begin{gathered}
W_{j}=C V_{j} / \sum_{j=1}^{n} C V_{j} \\
C V_{j}=\sigma_{j} / x_{j}
\end{gathered}
$$

where, $W_{j}$ is the weight of $j$ th evaluation index; $C V_{j}$ is the coefficient of variation of the $j$ th evaluation index; $\sigma_{j}$ is the standard deviation of $j$ th evaluation index, and $x_{j}$ is the average of $j$ th evaluation index.

Comparing the rank-sum ratio, the evaluation object was sorted directly.

\subsection{Statistical analysis}

The data were analyzed using SPSS 19.0 (Chicago, US) for two-way analysis of variance (ANOVA) and PCA; the GRA and rank-sum ratio method (RSR) were conducted in Microsoft Excel 2010 (Microsoft, USA). The differences between means of the same column were evaluated for significance using Duncan's multiple range tests at a significance level of 0.05 .

\section{Results}

\subsection{Effects of water stress on quality and yield of different} bunches of tomatoes in different growth periods

Tomato quality, except $\mathrm{OA}$ and $\mathrm{FN}$, was increased under water stress at all three growth stages compared to control. Within contrast, a decline in yield was discovered. At the same growth stage, mild water stress had fewer negative effects on yield than moderate water stress. The effects of water stress, growth stages, and the cross effects of water stress and growth stages were highly significant on L, TSS, and yield in the second bunch of fruits, and highly significant on SS, TSS, and yield in the third bunch. Nevertheless, the combined effect of water stress and growth stage had no effect on the content of SS in the second bunch of fruits or on L in the third bunch. Neither factor had an effect on the content of OA in either bunch of fruits. Water stress and growth stage had apparent effects on the content of VC and SAR, but the interaction effect of both factors was not significant. Neither water stress nor growth stage had an effect on FSI in the second bunch of fruits. Only growth stage had a significant effect on FCI in the second bunch of fruits. The effects of water stress on FSI and FCI were significant in the third bunch of fruits (Table 2).

\begin{tabular}{|c|c|c|c|c|c|c|c|c|c|c|c|}
\hline \multicolumn{2}{|c|}{ Treatments } & $\mathrm{VC} / \mathrm{mg} \cdot(100 \mathrm{~g})^{-1}$ & $\mathrm{SS} / \%$ & $\mathrm{~L} / \mathrm{mg} \cdot \mathrm{kg}^{-1}$ & $\mathrm{OA} / \mathrm{g} \cdot(100 \mathrm{~g})^{-1}$ & $\mathrm{~F} / \mathrm{kg} \cdot \mathrm{cm}^{-2}$ & $\mathrm{TSS} / \%$ & FSI & FCI & SAR & Yield $/ \mathrm{t} \cdot \mathrm{hm}^{-2}$ \\
\hline \multirow{9}{*}{ Second } & WS (CK) & $15.40 \mathrm{~h}$ & $1.953 \mathrm{efg}$ & $22.23 \mathrm{hi}$ & $0.47 \mathrm{a}$ & $6.73 b c$ & $4.19 \mathrm{~g}$ & $0.7558 \mathrm{~d}$ & $44.79 \mathrm{ef}$ & $4.26 \mathrm{e}$ & $26.51 \mathrm{a}$ \\
\hline & W1S1 & $21.27 \mathrm{bc}$ & $2.56 \mathrm{bcd}$ & $29.47 \mathrm{efg}$ & $0.37 \mathrm{bcde}$ & $7.42 \mathrm{a}$ & $6.95 \mathrm{~b}$ & $0.8427 \mathrm{abc}$ & $46.99 \mathrm{~cd}$ & $6.93 \mathrm{bcd}$ & $23.96 \mathrm{~b}$ \\
\hline & W2S1 & $19.00 \mathrm{efg}$ & $2.43 \mathrm{~cd}$ & $24.83 \mathrm{ghi}$ & $0.43 \mathrm{ab}$ & $6.00 \mathrm{def}$ & $5.60 \mathrm{de}$ & $0.7623 \mathrm{c}$ & $44.95 \mathrm{ef}$ & $5.64 \mathrm{cde}$ & $18.68 \mathrm{f}$ \\
\hline & W1S2 & $21.07 \mathrm{bcd}$ & $3.02 \mathrm{a}$ & $20.57 \mathrm{i}$ & $0.44 \mathrm{ab}$ & $6.92 \mathrm{ab}$ & $6.86 \mathrm{~b}$ & $0.7962 \mathrm{~cd}$ & $45.17 \mathrm{ef}$ & $6.89 \mathrm{bcd}$ & $20.68 \mathrm{~cd}$ \\
\hline & W2S2 & $20.53 \mathrm{bcde}$ & $2.90 \mathrm{ab}$ & $26.97 \mathrm{fgh}$ & $0.41 \mathrm{abc}$ & $5.92 \mathrm{ef}$ & $7.07 \mathrm{~b}$ & $0.8933 \mathrm{ab}$ & $44.32 \mathrm{f}$ & $7.14 \mathrm{bcd}$ & $20.16 \mathrm{de}$ \\
\hline & W2S3 & $21.50 \mathrm{ab}$ & $2.84 \mathrm{ab}$ & $27.00 \mathrm{fgh}$ & $0.39 \mathrm{bcd}$ & $6.09 \mathrm{cdef}$ & $7.23 b$ & $0.8350 \mathrm{abcd}$ & $46.31 \mathrm{de}$ & $7.26 \mathrm{bc}$ & $16.89 \mathrm{~g}$ \\
\hline & W & $* *$ & $*$ & $* *$ & ns & $* *$ & $* *$ & ns & ns & $* *$ & $* *$ \\
\hline & $\mathrm{S}$ & $*$ & $* *$ & $* *$ & $\mathrm{~ns}$ & $\mathrm{~ns}$ & $* *$ & ns & $*$ & $*$ & $* *$ \\
\hline & $\mathrm{W}^{*} \mathrm{~S}$ & ns & ns & $* *$ & ns & ns & $* *$ & $*$ & ns & $\mathrm{ns}$ & $* *$ \\
\hline \multirow{9}{*}{ Third } & WS (CK) & $17.27 \mathrm{~g}$ & $1.76 \mathrm{fg}$ & $30.90 \mathrm{ef}$ & $0.34 \mathrm{cdef}$ & $5.10 \mathrm{gh}$ & $4.37 \mathrm{~g}$ & $0.7947 \mathrm{~cd}$ & $47.57 \mathrm{bcd}$ & $5.18 \mathrm{de}$ & $26.25 \mathrm{a}$ \\
\hline & W1S1 & $20.57 \mathrm{bcde}$ & $2.19 \mathrm{def}$ & $42.30 \mathrm{ab}$ & $0.28 \mathrm{fg}$ & $6.02 \mathrm{def}$ & $5.10 \mathrm{ef}$ & $0.8844 \mathrm{ab}$ & $48.05 \mathrm{abc}$ & $7.82 b$ & $24.19 b$ \\
\hline & W1S2 & $19.45 \mathrm{cdef}$ & $2.75 \mathrm{abc}$ & $36.23 \mathrm{~cd}$ & $0.29 \mathrm{efg}$ & $5.66 f g$ & $6.30 \mathrm{c}$ & $0.8323 \mathrm{abcd}$ & $48.88 \mathrm{ab}$ & $9.48 \mathrm{a}$ & $21.60 \mathrm{c}$ \\
\hline & W2S2 & $18.53 \mathrm{fg}$ & $2.02 \mathrm{efg}$ & $39.80 \mathrm{bc}$ & $0.24 \mathrm{~g}$ & $4.63 \mathrm{~h}$ & $5.63 \mathrm{~d}$ & $0.8312 \mathrm{abcd}$ & $48.17 \mathrm{abc}$ & $8.42 \mathrm{ab}$ & $18.92 \mathrm{f}$ \\
\hline & W1S3 & $21.04 \mathrm{bcd}$ & $2.26 \mathrm{de}$ & $46.63 a$ & $0.29 \mathrm{fg}$ & $6.64 \mathrm{bcd}$ & $6.87 \mathrm{~b}$ & $0.8326 \mathrm{abcd}$ & $49.36 \mathrm{a}$ & $7.79 b$ & $21.39 \mathrm{c}$ \\
\hline & W2S3 & $19.38 \mathrm{def}$ & $2.18 \mathrm{def}$ & $41.67 b$ & $0.30 \mathrm{efg}$ & $5.14 \mathrm{gh}$ & $6.73 b c$ & $0.8131 \mathrm{bcd}$ & 47.79abcd & $7.27 b c$ & $19.38 \mathrm{ef}$ \\
\hline & W & $* *$ & $* *$ & $* *$ & ns & $* *$ & $* *$ & $*$ & $*$ & $*$ & $* *$ \\
\hline & $\mathrm{S}$ & $* *$ & $* *$ & $*$ & ns & $* *$ & $* *$ & ns & $\mathrm{ns}$ & $* *$ & $* *$ \\
\hline & $\mathrm{W}^{*} \mathrm{~S}$ & ns & $* *$ & ns & ns & ns & $* *$ & ns & ns & ns & $* *$ \\
\hline
\end{tabular}

Table 2 Effects of water stress during different growth period on quality and yield in the second and third bunches tomato

Notes: second, third: the second and third bunch of fruits; VC: vitamin C, SS: soluble sugar; L: lycopene; OA: organic acid; F: firmness; TSS: total soluble solids; FSI: fruit shape index; FCI: fruit color index; SAR: ratio of sugar and acid; *: significant effects $(p<0.05)$; **: extremely significant effects $(p<0.01)$; ns: not significant; W, S and $\mathrm{W}^{*} \mathrm{~S}$ : significant level of two-way ANOVA of water stress effect, growth stages effect, the cross effect of two factors; letters following the indices of each treatment are the significant differences through the Duncan's multiple range tests at 0.05 level.

During the same growth stage, fruit quality was higher under W1 than W2 except for L, OA, FSI, and SAR in the second bunch of fruits and for $\mathrm{L}$ and $\mathrm{OA}$ in the third bunch. The content of VC increased, ranging from $23.28 \%$ (W2S1) to $49.35 \%$ (W1S3) in the second bunch, and from $5.73 \%$ (W2S1) to $21.83 \%$ (W1S3) for different treatments in the third bunch; lycopene content increased from $17.25 \%$ (W1S2) to $50.91 \%$ (W1S3) in the third bunch, decreased in W1S2 treatment, but was not significantly different compared to control in the second bunch. High lycopene content was recorded with water stress during the fruit expanding stage. FCI had less pronounced changes among the seven treatments (Table 2).

The fruit yield of the two bunches was slightly different. The content of VC, SS, OA, TSS, and F in the second bunch of fruits was significantly higher than in the third under water stress without considering control treatment. Lycopene content, FSI, and FCI in the second bunch of fruits were significantly lower than in the third. The flavor quality in the second bunch had a better result, and the appearance quality in the third bunch was much better than in the second (Table 2).

The binomial distribution confidence test method was used for 
the confidence detection of each index. The Pearson correlation coefficient was used to analyze the correlation of tomato quality parameters. The results showed significantly positive correlations between $\mathrm{VC}$ and $\mathrm{L}, \mathrm{VC}$ and $\mathrm{F}, \mathrm{SS}$ and $\mathrm{L}, \mathrm{L}$ and F, L and SAR, F and TSS, and FSI and SAR. Highly significant correlations were found between SS and TSS, SS and SAR, L and FSI, TSS and SAR, and FSI and SAR. Furthermore, OA and SAR had a highly significant negative correlation (Table 3).

Table 3 Correlation analysis for main quality characteristics of the third bunch of tomato fruits

\begin{tabular}{|c|c|c|c|c|c|c|c|c|c|}
\hline & $\mathrm{VC}$ & SS & $\mathrm{L}$ & $\mathrm{F}$ & TSS & $\mathrm{OA}$ & FSI & $\mathrm{FCI}$ & SAR \\
\hline $\mathrm{VC}$ & 1 & & & & & & & & \\
\hline SS & 0.321 & 1 & & & & & & & \\
\hline $\mathrm{F}$ & $0.428 *$ & 0.288 & $0.392 *$ & 1 & & & & & \\
\hline TSS & 0.285 & $0.814 * *$ & 0.356 & $0.454 *$ & 1 & & & & \\
\hline $\mathrm{OA}$ & -0.187 & -0.099 & -0.252 & 0.111 & -0.132 & 1 & & & \\
\hline FCI & -0.153 & 0.204 & 0.374 & 0.179 & 0.232 & 0.133 & 0.066 & 1 & \\
\hline SAR & 0.29 & $0.880 * *$ & $0.427 *$ & 0.181 & $0.766^{* *}$ & $-0.509 * *$ & $0.444 *$ & 0.119 & 1 \\
\hline
\end{tabular}

Note: * means the significant level of $p<0.05$; ** means the extremely significant level of $p<0.01$.

\subsection{Comprehensive evaluation of tomato quality by PCA}

The main components (vitamin $\mathrm{C}$, soluble solids, lycopene, organic acid, firmness, total soluble solids, shape index, color index, ratio of sugar and acid) were extracted by PCA (Table 4). The results showed that the cumulative variance contribution of the first three principal components reached $94.58 \%, 94.83 \%$ and $93.78 \%$ in the second and third bunches of fruits and the overall values retained most of the raw data. Thus, the original nine variables were replaced with three principal components for the quality evaluation of each treatment.

Table 4 Total variance explanation of principal component analysis in different bunches

\begin{tabular}{|c|c|c|c|c|c|c|c|}
\hline \multirow{2}{*}{\multicolumn{2}{|c|}{$\begin{array}{c}\text { Principal } \\
\text { components }\end{array}$}} & \multicolumn{3}{|c|}{ Initial eigenvalue } & \multicolumn{3}{|c|}{ Extraction sums of the squared loadings } \\
\hline & & \multirow{2}{*}{$\begin{array}{c}\text { Eigenvalue } \\
6.36\end{array}$} & \multirow{2}{*}{$\begin{array}{c}\text { Variance contribution } \\
70.667 \%\end{array}$} & \multirow{2}{*}{$\begin{array}{c}\begin{array}{c}\text { Cumulative variance } \\
\text { contribution }\end{array} \\
70.667 \%\end{array}$} & \multirow{2}{*}{$\begin{array}{c}\text { Eigenvalue } \\
6.36\end{array}$} & \multirow{2}{*}{$\begin{array}{c}\text { Variance contribution } \\
70.667 \%\end{array}$} & \multirow{2}{*}{$\begin{array}{c}\begin{array}{c}\text { Cumulative variance } \\
\text { contribution }\end{array} \\
70.667 \%\end{array}$} \\
\hline & 1 & & & & & & \\
\hline & 2 & 1.342 & $14.907 \%$ & $85.574 \%$ & 1.342 & $14.907 \%$ & $85.574 \%$ \\
\hline & 3 & 0.811 & $9.008 \%$ & $94.583 \%$ & 0.811 & $9.008 \%$ & $94.583 \%$ \\
\hline \multirow[t]{8}{*}{ Second } & 5 & 0.194 & $2.157 \%$ & $99.659 \%$ & & & \\
\hline & 6 & 0.031 & $0.341 \%$ & $100 \%$ & & & \\
\hline & 7 & $1.00 \mathrm{E}-13$ & $1.01 \mathrm{E}-13 \%$ & $100 \%$ & & & \\
\hline & 8 & $-1.00 \mathrm{E}-13$ & $-1.00 \mathrm{E}-13 \%$ & $100 \%$ & & & \\
\hline & 9 & $-1.00 \mathrm{E}-13$ & $-1.03 \mathrm{E}-13 \%$ & $100 \%$ & & & \\
\hline & 1 & 6.501 & $72.233 \%$ & $72.233 \%$ & 6.501 & $72.233 \%$ & $72.233 \%$ \\
\hline & 3 & 0.901 & $10.016 \%$ & $94.830 \%$ & 0.901 & $10.016 \%$ & $94.83 \%$ \\
\hline & 4 & 0.288 & $3.201 \%$ & $98.031 \%$ & & & \\
\hline \multirow[t]{9}{*}{ Third } & 5 & 0.098 & $1.087 \%$ & $99.118 \%$ & & & \\
\hline & 6 & 0.079 & $0.882 \%$ & $100 \%$ & & & \\
\hline & 7 & $1.00 \mathrm{E}-13$ & $1.02 \mathrm{E}-13 \%$ & $100 \%$ & & & \\
\hline & 8 & $1.00 \mathrm{E}-13$ & $1.00 \mathrm{E}-13 \%$ & $100 \%$ & & & \\
\hline & 9 & $-1.00 \mathrm{E}-13$ & $-1.05 \mathrm{E}-13 \%$ & $100 \%$ & & & \\
\hline & 1 & 6.221 & $69.125 \%$ & $69.125 \%$ & 6.221 & $69.125 \%$ & $69.125 \%$ \\
\hline & 2 & 1.228 & $13.641 \%$ & $82.766 \%$ & 1.228 & $13.641 \%$ & $82.766 \%$ \\
\hline & 3 & 0.991 & $11.01 \%$ & $93.776 \%$ & 0.991 & $11.01 \%$ & $93.776 \%$ \\
\hline & 4 & 0.413 & $4.594 \%$ & $98.369 \%$ & & & \\
\hline \multirow{3}{*}{ Average } & 7 & $1.00 \mathrm{E}-13$ & $1.02 \mathrm{E}-13 \%$ & $100 \%$ & & & \\
\hline & 8 & $-1.00 \mathrm{E}-13$ & $-1.02 \mathrm{E}-13 \%$ & $100 \%$ & & & \\
\hline & 9 & $-1.00 \mathrm{E}-13$ & $-1.02 \mathrm{E}-13 \%$ & $100 \%$ & & & \\
\hline
\end{tabular}

Note: second: the second bunch of fruits, third: the third bunch of fruit; average: the average value of the two bunches.

The principal component load matrix reflects the loading information of different indices in each principal component. The variance contribution of the first principal component reached
$72.23 \%$ (in the third bunch of fruits for example), reflecting all fruit quality indices including vitamin $\mathrm{C}$, soluble solids, lycopene, organic acid, firmness, total soluble solids, shape index, color index, 
and ratio of sugar and acid (Tables 4 and 5).

Table 5 Principal component loading matrix in different bunches

\begin{tabular}{|c|c|c|c|c|}
\hline \multirow{2}{*}{\multicolumn{2}{|c|}{ Index variables }} & \multicolumn{3}{|c|}{ Principal component } \\
\hline & & \multirow{2}{*}{$\begin{array}{c}1 \\
0.956\end{array}$} & \multirow{2}{*}{$\begin{array}{c}2 \\
-0.107\end{array}$} & \multirow{2}{*}{$\begin{array}{c}3 \\
0.224\end{array}$} \\
\hline \multirow{9}{*}{ Second } & $X 1$ & & & \\
\hline & $X 2$ & 0.839 & -0.394 & 0.348 \\
\hline & $X 3$ & 0.814 & 0.282 & -0.502 \\
\hline & $X 4$ & -0.919 & -0.213 & 0.168 \\
\hline & $X 5$ & 0.033 & 0.837 & 0.516 \\
\hline & $X 6$ & 0.981 & -0.129 & 0.142 \\
\hline & $X 7$ & 0.890 & -0.096 & -0.188 \\
\hline & $X 8$ & 0.761 & 0.525 & -0.111 \\
\hline & $X 9$ & 0.950 & -0.219 & 0.160 \\
\hline \multirow{9}{*}{ Third } & $X 1$ & 0.859 & 0.210 & -0.179 \\
\hline & $X 2$ & 0.867 & -0.257 & 0.415 \\
\hline & $X 3$ & 0.801 & 0.350 & -0.450 \\
\hline & $X 4$ & -0.660 & 0.482 & 0.552 \\
\hline & $X 5$ & 0.725 & 0.586 & 0.286 \\
\hline & $X 6$ & 0.923 & -0.261 & 0.225 \\
\hline & $X 7$ & 0.920 & 0.266 & -0.147 \\
\hline & $X 8$ & 0.950 & 0.038 & 0.163 \\
\hline & $X 9$ & 0.898 & -0.429 & 0.094 \\
\hline \multirow{9}{*}{ Average } & $X 1$ & 0.949 & 0.014 & 0.024 \\
\hline & $X 2$ & 0.781 & -0.305 & 0.539 \\
\hline & $X 3$ & 0.838 & 0.194 & -0.448 \\
\hline & $X 4$ & -0.850 & 0.145 & 0.427 \\
\hline & $X 5$ & 0.395 & 0.818 & 0.317 \\
\hline & $X 6$ & 0.935 & -0.234 & 0.148 \\
\hline & $X 7$ & 0.898 & -0.039 & -0.324 \\
\hline & $X 8$ & 0.817 & 0.495 & 0.089 \\
\hline & $X 9$ & 0.884 & -0.325 & 0.284 \\
\hline
\end{tabular}

Note: $X 1-X 9$ mean vitamin $\mathrm{C}$, soluble solids, lycopene, organic acid, firmness, total soluble solids, shape index, color index, ratio of sugar and acid respectively, the same as below.
The coefficients of the three principal components were obtained through the principal component load vector divided by the arithmetic square of the eigenvalues; the ratio of the corresponding eigenvalues of each principal component and the sum of the three principal component eigenvalues were regarded as weights and then each principal component comprehensive score model of the third bunch was obtained:

$$
\begin{aligned}
F_{i}= & 0.2619 X_{i 1}+0.2876 X_{i 2}+0.2004 X_{i 3}-0.2281 X_{i 4}+0.3252 X_{i 5}+ \\
& 0.2759 X_{i 6}+0.2887 X_{i 7}+0.2331 X_{i 8}+0.2818 X_{i 9}
\end{aligned}
$$

where, $F_{i}$ is the overall score of the ith component in the third bunch, and $X_{i 1}-X_{i 9}$ are the standardized values of the 9 tomato quality indicators of the $i t h$ treatment in the third bunch.

The weight calculated by PCA was the common factor variance of each evaluation index. For the third bunch of fruits, the maximal weight of 0.118 belonged to $\mathrm{OA}$, and the minimal weight of 0.094 belonged to $\mathrm{VC}$; the weights of each index were distributed evenly (Table 6). The overall score of each treatment was calculated using the comprehensive score model. Through the comprehensive evaluation, the best two treatments were W1S3 and W1S1 in the second bunch, the average of the second and third bunch, and W1S3 and W1S2 in the third bunch. The two worst treatments were W2S1 and WS in the second bunch, the average of the second and third bunch, and W2S3 and WS in the third bunch. There were some differences in the ranking among three bunches based on PCA method. The trend between the second bunch and the average of the second and third bunches was almost same, while W1S2 ranked the fifth in the second bunch, but ranked second in the third bunch; W2S3 ranked third in the second bunch but ranked sixth in the third bunch (Table 7).

\subsection{Comprehensive evaluation of tomato quality by GRA}

Grey correlation coefficient $\gamma_{i j}$ of each parameter was calculated according to Equation (5), and the weighed correlation $\gamma_{i}$ was also calculated. W1S3 and W2S3 were the best two treatments related to fruit quality in terms of the second bunch of fruits, W1S3 and W1S2 were the best two treatments in the third bunch, and W1S3 and W1S1 were the best two treatments for the average of both bunches (Table 8). W2S1 and WS were the worst two treatments in three bunches of fruit. In addition, the ranking between the third bunch and the average of the second and third bunches showed the same trend but differed from the second bunch in terms of W1S2 treatment (Table 8).

\begin{tabular}{|c|c|c|c|c|c|c|c|c|c|c|}
\hline & variables & $X 1$ & $X 2$ & $X 3$ & $X 4$ & $X 5$ & $X 6$ & $X 7$ & $X 8$ & $X 9$ \\
\hline \multirow{2}{*}{ Second } & Communalities & 0.975 & 0.980 & 0.993 & 0.919 & 0.968 & 0.999 & 0.836 & 0.867 & 0.976 \\
\hline & Weights & 0.115 & 0.115 & 0.117 & 0.108 & 0.114 & 0.117 & 0.098 & 0.102 & 0.115 \\
\hline \multirow{2}{*}{ Third } & Communalities & 0.777 & 0.925 & 0.923 & 0.973 & 0.922 & 0.935 & 0.894 & 0.954 & 0.921 \\
\hline & Weights & 0.094 & 0.112 & 0.112 & 0.118 & 0.112 & 0.114 & 0.109 & 0.116 & 0.112 \\
\hline \multirow{2}{*}{ Average } & Communalities & 0.902 & 0.995 & 0.941 & 0.927 & 0.925 & 0.95 & 0.914 & 0.92 & 0.967 \\
\hline & Weights & 0.100 & 0.111 & 0.105 & 0.103 & 0.103 & 0.106 & 0.102 & 0.102 & 0.107 \\
\hline
\end{tabular}

Table 6 Weight of each index in different bunches

\begin{tabular}{|c|c|c|c|c|c|c|c|c|}
\hline & Treatments & WS & W1S1 & W2S1 & $\mathrm{W} 1 \mathrm{~S} 2$ & $\mathrm{~W} 2 \mathrm{~S} 2$ & W1S3 & W2S3 \\
\hline \multirow{2}{*}{ Second } & Comprehensive scores & -3.088 & 1.192 & -1.532 & -0.253 & 0.173 & 2.757 & 0.751 \\
\hline & Comprehensive ranks & 7 & 2 & 6 & 5 & 4 & 1 & 3 \\
\hline \multirow{2}{*}{ Third } & Comprehensive scores & -3.01 & 1.124 & -1.025 & 1.334 & -0.129 & 2.121 & -0.414 \\
\hline & Comprehensive ranks & 7 & 3 & 5 & 2 & 4 & 1 & 6 \\
\hline Average & Comprehensive scores & -3.027 & 1.138 & -1.453 & 0.344 & -0.108 & 2.778 & 0.327 \\
\hline
\end{tabular}

Table 7 Rank of the comprehensive fruit quality in different bunches by PCA method 
Table 8 Rank of the comprehensive fruit quality in different bunches by GRA method

\begin{tabular}{|c|c|c|c|c|c|c|c|c|c|c|c|c|}
\hline \multicolumn{2}{|c|}{ Treatments } & \multirow{2}{*}{$\begin{array}{c}X 1 \\
0.417\end{array}$} & \multirow{2}{*}{$\begin{array}{c}X 2 \\
0.410\end{array}$} & \multirow{2}{*}{$\begin{array}{c}X 3 \\
0.419\end{array}$} & \multirow{2}{*}{$\begin{array}{c}X 4 \\
0.609\end{array}$} & \multirow{2}{*}{$\begin{array}{c}X 5 \\
0.507\end{array}$} & \multirow{2}{*}{$\begin{array}{c}X 6 \\
0.390\end{array}$} & \multirow{2}{*}{$\begin{array}{c}X 7 \\
0.473\end{array}$} & \multirow{2}{*}{$\begin{array}{c}X 8 \\
0.499\end{array}$} & \multirow{2}{*}{$\begin{array}{c}X 9 \\
0.362\end{array}$} & \multirow{2}{*}{$\begin{array}{c}\begin{array}{c}\text { Weight correlation } \\
\text { degree }\end{array} \\
0.454\end{array}$} & \multirow{2}{*}{$\begin{array}{c}\text { Ranking } \\
7\end{array}$} \\
\hline & WS & & & & & & & & & & & \\
\hline & W1S1 & 0.497 & 0.477 & 0.488 & 0.551 & 0.531 & 0.515 & 0.500 & 0.511 & 0.481 & 0.506 & 3 \\
\hline & W2S1 & 0.469 & 0.464 & 0.446 & 0.591 & 0.478 & 0.461 & 0.475 & 0.500 & 0.430 & 0.479 & 6 \\
\hline \multirow[t]{7}{*}{ Second } & W1S2 & 0.495 & 0.518 & 0.400 & 0.595 & 0.514 & 0.512 & 0.486 & 0.501 & 0.479 & 0.500 & 5 \\
\hline & W2S2 & 0.488 & 0.508 & 0.466 & 0.578 & 0.475 & 0.519 & 0.515 & 0.497 & 0.488 & 0.504 & 4 \\
\hline & W1S3 & 0.517 & 0.525 & 0.517 & 0.553 & 0.501 & 0.561 & 0.521 & 0.522 & 0.514 & 0.526 & 1 \\
\hline & W2S3 & 0.500 & 0.503 & 0.466 & 0.568 & 0.482 & 0.525 & 0.498 & 0.508 & 0.508 & 0.506 & 2 \\
\hline & WS & 0.492 & 0.368 & 0.404 & 0.644 & 0.470 & 0.391 & 0.693 & 0.832 & 0.333 & 0.514 & 7 \\
\hline & W1S1 & 0.695 & 0.472 & 0.670 & 0.783 & 0.633 & 0.470 & 0.975 & 0.861 & 0.525 & 0.676 & 4 \\
\hline & W2S1 & 0.539 & 0.382 & 0.622 & 0.707 & 0.557 & 0.449 & 0.823 & 0.873 & 0.351 & 0.589 & 6 \\
\hline \multirow[t]{7}{*}{ Third } & W1S2 & 0.610 & 0.743 & 0.496 & 0.879 & 0.557 & 0.707 & 0.788 & 0.915 & 0.823 & 0.724 & 2 \\
\hline & W2S2 & 0.554 & 0.425 & 0.585 & 0.547 & 0.416 & 0.552 & 0.785 & 0.868 & 0.604 & 0.593 & 5 \\
\hline & W1S3 & 0.739 & 0.494 & 0.894 & 0.879 & 0.824 & 0.929 & 0.789 & 0.950 & 0.522 & 0.780 & 1 \\
\hline & W2S3 & 0.605 & 0.469 & 0.646 & 1.000 & 0.476 & 0.862 & 0.736 & 0.845 & 0.469 & 0.679 & 3 \\
\hline & WS & 0.466 & 0.432 & 0.456 & 0.601 & 0.510 & 0.429 & 0.515 & 0.542 & 0.422 & 0.486 & 7 \\
\hline & W1S1 & 0.528 & 0.493 & 0.531 & 0.549 & 0.542 & 0.515 & 0.542 & 0.549 & 0.530 & 0.531 & 2 \\
\hline & W2S1 & 0.499 & 0.466 & 0.509 & 0.591 & 0.506 & 0.481 & 0.524 & 0.544 & 0.464 & 0.510 & 6 \\
\hline \multirow[t]{4}{*}{ Average } & W1S2 & 0.514 & 0.542 & 0.473 & 0.586 & 0.525 & 0.536 & 0.527 & 0.547 & 0.559 & 0.534 & 3 \\
\hline & W2S2 & 0.506 & 0.502 & 0.513 & 0.551 & 0.481 & 0.528 & 0.541 & 0.543 & 0.544 & 0.523 & 5 \\
\hline & W1S3 & 0.541 & 0.524 & 0.557 & 0.548 & 0.538 & 0.573 & 0.545 & 0.558 & 0.555 & 0.549 & 1 \\
\hline & W2S3 & 0.532 & 0.508 & 0.520 & 0.567 & 0.488 & 0.551 & 0.530 & 0.547 & 0.529 & 0.530 & 4 \\
\hline
\end{tabular}

\subsection{Correlation analysis between PCA and GRA}

Spearman correlation was used to represent the close relationship of the rank of each quality factor in different treatments. In addition, the Spearman correlation coefficient of the PCA and GRA methods was calculated according to Equation (7). The value of the second bunch and the average of the second and third bunches was 0.964 and the value of the third bunch was 0.893 , both of which indicated that there was a close correlation between the comprehensive ranking conducted by the two evaluation methods.

\subsection{Comprehensive evaluation of tomato yield and quality}

The quality calculated by PCA and GRA was regarded as the quantitative indicator and combined tomato yield of different treatments for evaluation. The weights of fruit quality and yield were given by Equations (10) and (11). The weight of yield was less than the quality in PCA or GRA in terms of the third bunch. The result showed that the weight of yield was less than quality in PCA. However, the opposite result occurred in GRA of the second bunch and the average of the second and third bunches. After determining the rank of quality and yield, the rank-sum ratio was calculated using Equation (9).

The ranking of different treatments is shown in Table 8. For PCA, there was a difference of the ranking between the second and third bunch: W2S2 of the second bunch was ranked last, but it was fourth in the third bunch. The ranking between the third bunch and the average of the second and third bunches had the same trend with only a slight difference.

For GRA, the second bunch, third bunch and the average of the second and third bunches had a similar trend with only a slight difference in ranking among them. In the second bunch, there was an obvious difference of the ranking between PCA and GRA: W2S3 was third in PCA, but it was sixth in GRA; WS was fifth in
PCA, but second in GRA. In the third bunch, only the ranking of W2S2 was slightly different: it was fourth in PCA but last in GRA.

In terms of the average of the second and third bunch, the general trend was the same as the second bunch. The top ranking of the second bunch was W1S3 from PCA and W1S1 from GRA; and the last was W2S2 from PCA and W2S1 from GRA. W1S3 of the third bunch ranked first with PCA and GRA; and W2S1 and W2S2 ranked last from PCA and GRA, respectively. The first ranking of the average of the second and third bunches was the same as the second bunch, and last was W2S1 from PCA and W2S3 from GRA method (Table 9).

\section{Discussion}

Irrigation intervals, amounts, and techniques have extensive influence on tomato fruit quality and yield. Numerous studies have reported negative impacts on crop yield of tomato under water stress $^{[33,34]}$. In this study, tomatoes were exposed to water stress for 18 days at the three growth stages. The tomato yield was declined under water stress condition, however, the fruit quality was enhanced. Water is a crucial factor affecting tomato fruit quality, and in particular, SS, F, and TSS were affected by water stress; similar conclusions were drawn by Ghanbarpour, et al. ${ }^{[35]}$ and Griñán, et al. ${ }^{[36]}$. Regardless of the growth period, water stress enhanced fruit quality indicators except $\mathrm{F}$ compared to control (Table 1). Moderate water stress for the whole growing season or for part of it would significantly enhance tomato quality in terms of $\mathrm{TSS}^{[37]}$. Taste was greatly improved by water stress, which was mainly reflected in the content of SS and TSS. The content of SS and TSS increased under water stress during the fruit expanding stage, the same conclusion was shown for grapefruits and grapes ${ }^{[38,39]}$. This is because the product of the accumulation of photosynthesis would be more distributed to the reproductive 
Table 9 Rank for comprehensive evaluation in different bunches

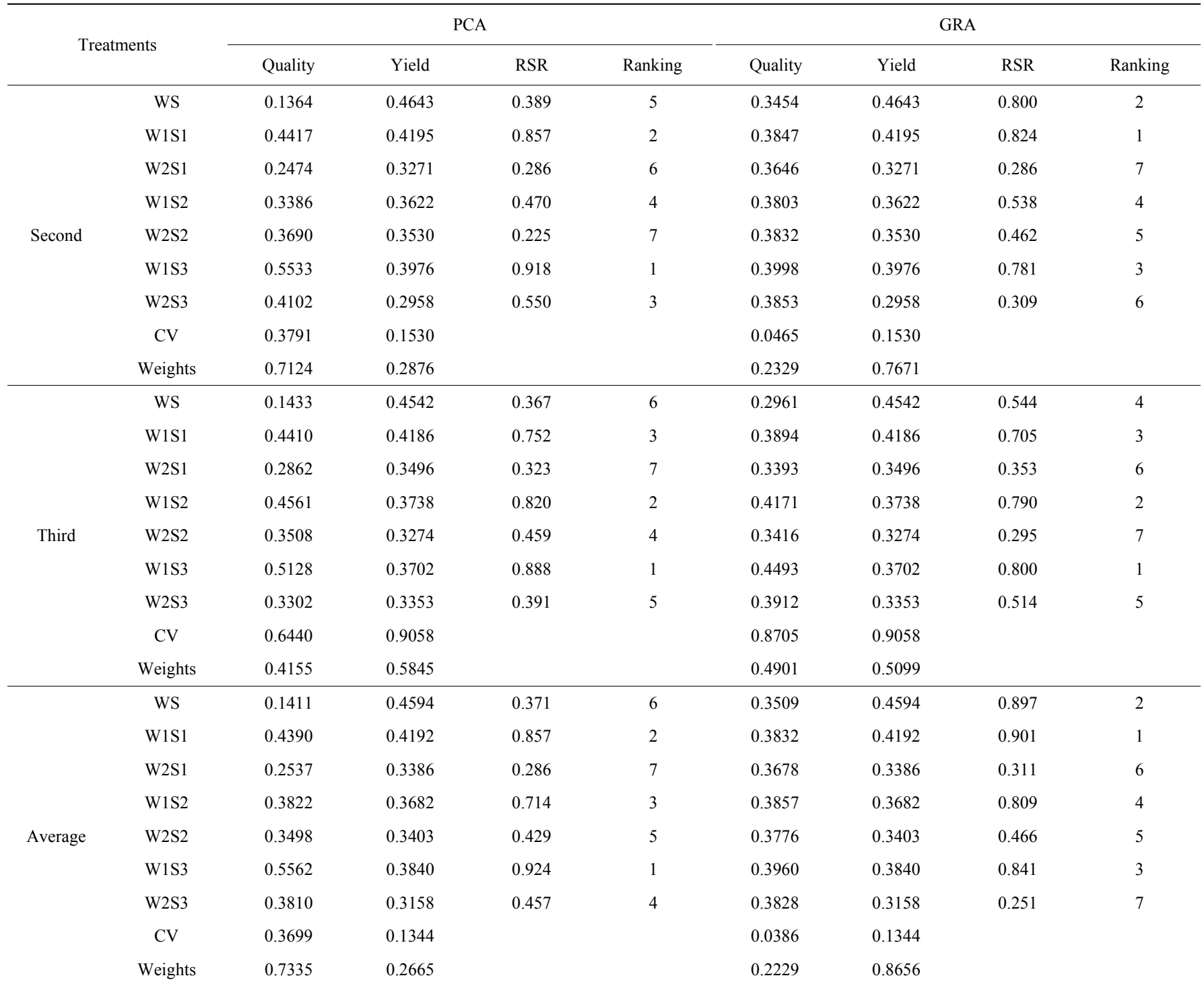

organs under water stress, eventually leading to an apparent enhancement in the sugar content. The content of VC increased significantly in the three growth periods; the synthesis of $\mathrm{VC}$ begins with glucose and has an intimate connection with carbohydrate metabolism. It can be inferred that the higher sugar accumulation during water stress promotes $\mathrm{VC}$ during the fruit mature stage ${ }^{[40]}$. Due to lower pressure of the cell wall and better epidermal elasticity, internal turgor is reduced, thereby enhancing the firmness of fruit ${ }^{[41]}$.

The high level of lycopene was observed under W1S3 and W2S3 treatments, apparently, lycopene synthesis was accompanied by tomato maturity. This suggests that lycopene synthesis was promoted by signaling to ethylene biosynthesis under water stress at the fruit expanding stage ${ }^{[42]}$, and the effects of water stress had more influence on fruit quality at fruit expanding stage than at growth stage. Inadequate irrigation reduces tomato yield, especially the the flowering and fruit expanding stages; similar results were obtained from a study on Sacha inchi ${ }^{[43]}$. Early florescence and the more mature buds increase the flower and fruit set percentages, which ultimately lays a vital foundation for the growth and maturation of fruit. For pear-jujube, moderate and severe deficit irrigation during the budding stage had no effect on fruit quality, but significantly reduced water consumption and increased fruit yield ${ }^{[44]}$. Water stress applied at the flowering stage affected photosynthesis and inhibited shoot development, but the effect of water stress was not significant at the seedling stage ${ }^{[45]}$ The compensation effect after water stress at the seedling stage meant that fruit yield at this stage was not reduced as much as at other stages. Therefore, the fruit yield of W1S1 would be less impacted.

In this study, the difference of fruit quality between the second and third bunches of tomatoes was significant. The content of VC, $\mathrm{SS}, \mathrm{OA}$, and $\mathrm{F}$ in the second bunch was higher than in the third bunch, while the value of lycopene and FCI in the third bunch was higher than that in the second. This indicated that under water stress the flavor quality of the second bunch was better than that of the third bunch, and the color quality had the opposite results compared to the flavor quality. Fruit quality is an integrated concept: a single trait cannot reflect the overall quality of fruit. In this experiment, two methods were used for evaluating fruit quality. The best treatment for comprehensive quality was W1S3, and the worst was WS (control) of the second bunch, the third bunch, and the average of the second and third bunch based on both PCA and GRA methods (Tables 6 and 7). In addition, the Spearman correlation coefficient of the two methods was close to 1, meaning that PCA and GRA were highly correlated. However, there was still a difference in ranking between the second and third bunch through PCA and GRA. The discrepancy means that it is not 
sufficient to analyze the fruit quality using only one bunch. The deviation would occur even if the aggregate value of a few bunches was used to evaluate the tomato quality (Tables 6 and 7). Chen et $a l .{ }^{[46]}$ found that the content of TSS, VC, and OA as well as SAR, F and FCI of tomato would significantly increase under inadequate irrigation at the flowering and fruit set stages, and at the fruit ripening stage. This finding explained why comprehensive quality of W1S3 (mild water stress at the fruit expanding stage) ranked first. In the rank-sum ratio method, there was an obvious difference of the ranking of all seven treatments except W1S1, W2S1, W2S2 between PCA and GRA in the second bunch (Table 8). Differences in ranks between PCA and GRA show that the weight of quality and yield was different in the two methods. Differences in rank between the different bunches was caused by differences in fruit quality.

\section{Conclusions}

Tomato yield was reduced by water stress over the whole growth period, but fruit quality was improved under water stress conditions. The tomato yield of water stress treatments was lower than that of the control, regardless of the growth stage when water stress was applied. The contents of SS and TSS increased at late growth stage, and the contents of $\mathrm{VC}$ and lycopene increased. The flavor quality of the second bunch fruit was better than that of the third bunch. In contrast, the appearance quality of the third bunch was better than that of the second bunch. There were discrepancies in the overall ranks between the two bunches. Hence, the data of only one bunch fruit cannot represent the quality of tomato in the comprehensive analysis of tomato fruit quality in the future. However, the fruit yield and quality should be considered together as a whole. The reasonable treatment selected was W1S3 from PCA, and W1S1 from GRA using the RSR method with higher fruit quality but lower yield compared to control. In summary, mild water stress applied at the seedling stage or fruit expanding stage was the optimal treatment for fruit quality and yield of greenhouse tomato in northwest China.

\section{Acknowledgements}

This study was financially supported by the 863 Program of National High-Tech R\&D Program of China (2013AA103004) and the Water and Technology Support Plan of Shaanxi Province, China (2014slkj-17).

\section{[References]}

[1] Chang T, Zhang Y, Zhang Z, Shao X, Wang W, Zhang J, et al. Effects of irrigation regimes on soil $\mathrm{NO}_{3}{ }^{-} \mathrm{N}$, electrical conductivity and crop yield in plastic greenhouse. Int J Agric \&Biol Eng, 2019; 12(1): 109-115.

[2] Hashem M S, El-Abedin T Z, Al-Ghobari H M. Assessing effects of deficitirrigation techniques on water productivity of tomato for subsurface drip irrigation system. Int J Agric \&Biol Eng, 2018; 11(4): 156-165.

[3] Zhu J, Wu H, Yang S, Wang C. Technology optimization of ultrasonic-assisted extraction for lycopene from lyophilized tomato powder. Transactions of the CSAE, 2013, 29(18): 284-291. (in Chinese)

[4] Shariffa Y N, Tan T B, Uthumporn U, Abas F, Mirhosseini H, Nehdi I A, et al. Producing a lycopene nanodispersion: Formulation development and the effects of high pressure homogenization. Food Research International, 2017; 101: 165-172.

[5] Zhu Z, Zhang Y, Liu J, Chen Y, Zhang X. Exploring the effects of selenium treatment on the nutritional quality of tomato fruit. Food Chemistry, 2018; 252(2018): 9-15.

[6] Wang F, Kang S, Du T, Li F, Qiu R. Determination of comprehensive quality index for tomato and its response to different irrigation treatments. Agricultural Water Management, 2011; 98(8): 1228-1238.

[7] Panigrahi B, Roy D P, Panda S N. Water use and yield response of tomato as influenced by drip and furrow irrigation. International Agricultural Engineering Journal, 2010; 19(1): 19-30.

[8] Ramlow M, Foster E J, Del Grosso S J, Cotrufo M F. Broadcast woody biochar provides limited benefits to deficit irrigation maize in Colorado. Agriculture, Ecosystems \& Environment, 2019; 269: 71-81.

[9] Buttaro D, Santamaria P, Signore A, Cantore V, Boari F, Montesano F F, et al. Irrigation management of greenhouse tomato and cucumber using tensiometer: effects on yield, quality and water use. Agriculture and Agricultural Science Procedia, 2015; 4: 440-444.

[10] Coyago-Cruz E, Corell M, Stinco C M, Hernanz D, Moriana A, Meléndez-Martínez A J. Effect of regulated deficit irrigation on quality parameters, carotenoids and phenolics of diverse tomato varieties (Solanum lycopersicum L.). Food Research International, 2017; 96: 72-83.

[11] El Jaouhari N, Abouabdillah A, Bouabid R, Bourioug M, Aleya L, Chaoui M. Assessment of sustainable deficit irrigation in a Moroccan apple orchard as a climate change adaptation strategy. Science of The Total Environment, 2018; 642: 574-581.

[12] Conesa M R, García-Salinas M D, de la Rosa J M, Fernández-Trujillo J P, Domingo R, Pérez-Pastor A. Effects of deficit irrigation applied during fruit growth period of late mandarin trees on harvest quality, cold storage and subsequent shelf-life. Scientia Horticulturae, 2014; 165: 344-351.

[13] Zhou H M, Zhang F C, Roger K, Wu L F, Gong D Z, Zhao N, et al. Peach yield and fruit quality is maintained under mild deficit irrigation in semi-arid China. Journal of Integrative Agriculture, 2017; 16(5): 1173-1183.

[14] Xing Y, Zhang F, Zhang Y, Li J, Qiang S, Wu L. Effect of irrigation and fertilizer coupling on greenhouse tomato yield, quality, water and nitrogen utilization under fertigation. Scientia Agricultura Sinica, 2015; 48(4): 713-726. (in Chinese)

[15] Papadaki A M, Bletsos F A, Eleftherohorinos I G, Menexes G, Lagopodi A L. Effectiveness of seven commercial rootstocks against verticillium wilt and their effects on growth, yield, and fruit quality of tomato. Crop Protection, 2017; 102: 25-31.

[16] Fan X, Gurtler J B, Sokorai K J B. Tomato type and post-treatment water rinse affect efficacy of acid washes against Salmonella enterica inoculated on stem scars of tomatoes and product quality. International Journal of Food Microbiology, 2018; 280: 57-65.

[17] Wang X, Bi J, Liu X, Lv J, Yang A. Application of grey correlation analysis for evaluating the overall quality of fuji apples from different growing areas. Food Science, 2013; 34(23): 88-91. (in Chinese)

[18] Cao Y, Jiang Y, Gao H, Chen H, Fang X, Mu H, et al. Development of a model for quality evaluation of litchi fruit. Computers and Electronics in Agriculture, 2014; 106: 49-55.

[19] Lan C-H, Huang Y-L, Ho S-H, Peng C-Y. Volatile organic compound identification and characterization by PCA and mapping at a high-technology science park. Environmental Pollution, 2014; 193: 156-164.

[20] Maćkiewicz A, Ratajczak W. Principal components analysis (PCA). Computers \& Geosciences, 1993; 19(3): 303-342.

[21] Li Y, Sun Y, Liao S, Zou G, Zhao T, Chen Y, et al. Effects of two slow-release nitrogen fertilizers and irrigation on yield, quality, and water-fertilizer productivity of greenhouse tomato. Agricultural Water Management, 2017; 186: 139-146.

[22] Wang P, Li J, Ding J, Liu G, Pan T, Du Q, et al Effect of water and fertilizer coupling on quality, yield and water use efficiency of tomato cultivated by organic substrate in bag. Scientia Agricultura Sinica, 2015; 48(2): 314-323. (in Chinese)

[23] Li W, Gao H, Chen H, Wu W, Fang X. Evaluation of comprehensive quality of different varieities of bayberry based on principle components analysis. Journal of Chinese Institute of Food Science and Technology, 2017; 17(6): 161-171. (in Chinese)

[24] Gong L, Meng X, Liu N, Bi J. Evaluation of apple quality based on principle component analysis and hierarchical cluster analysis. Transactions of the CSAE, 2014; 30(13): 276-285. (in Chinese)

[25] Liu K, Huang C, Leng J, Chen K, Yan Y, Gu Q, et al. Principle component analysis and comprehensive evaluation of the fruit quality of 'Jinkui' kiwifruit. Journal of Fruit Science, 2012; 29(5): 867-871.

[26] Bao J, Qiao G, Liu P, Chen N, Wen X. Evaluating fruit qualities of different sweet cherry cultivars. Journal of Huazhong Argicultural University, 2016; 35(3): 12-16. (in Chinese)

[27] Song J, Liu C, Jiang X, Li D. Comprehensive evaluation of vegetable soybean quality by principle component analysis and cluster analysis. Food Science, 2015; 36(13): 12-17. (in Chinese) 
[28] Huang Y, Shen L, Liu H. Grey relational analysis, principal component analysis and forecasting of carbon emissions based on long short-term memory in China. Journal of Cleaner Production, 2019; 209: 415-423.

[29] Liu M, Tian Q, Wang Z, Li H. Comprehensive evaluation of the quality of health care service of Henan Province in 2014 using TOPSIS combinde with rank-sum ratio method. Journal of Zhengzhou University (Medical Sciences), 2016; 51(5): 617-622. (in Chinese)

[30] Huang J, Li X. The korla fragrant pear color grading based on colorimeter. Northen Horticulture, 2018; 17: 38-44. (in Chinese)

[31] Li X, Wang Z, Zhang L, Zou C, Dorrell D D. State-of-health estimation for Li-ion batteries by combing the incremental capacity analysis method with grey relational analysis. Journal of Power Sources, 2019; 410-411: $106-114$.

[32] Ashok Kumar J , Abirami S. Aspect-based opinion ranking framework for product reviews using a Spearman's rank correlation coefficient method. Information Sciences, 2018; 460-461: 23-41.

[33] Sarker K K, Akanda M A R, Biswas S K, Roy D K, Khatun A, Goffar M A. Field performance of alternate wetting and drying furrow irrigation on tomato crop growth, yield, water use efficiency, quality and profitability. Journal of Integrative Agriculture, 2016; 15(10): 2380-2392.

[34] Martí R, Valcárcel M, Leiva-Brondo M, Lahoz I, Campillo C, Roselló S, et al. Influence of controlled deficit irrigation on tomato functional value. Food Chemistry, 2018; 252: 250-257.

[35] Ghanbarpour E, Rezaei M, Lawson S. Reduction of cracking in pomegranate fruit after foliar application of humic acid, calcium-boron and kaolin during water stress. Erwerbs-Obstbau, 2019; 61(1): 29-37.

[36] Griñán I, Morales D, Galindo A, Torrecillas A, Pérez-López D, Moriana A, et al. Effect of preharvest fruit bagging on fruit quality characteristics and incidence of fruit physiopathies in fully irrigated and water stressed pomegranate trees. Journal of the Science of Food and Agriculture, 2019; 99(3): 1425-1433.

[37] Patanè $C$, Tringali S, Sortino $O$. Effects of deficit irrigation on biomass, yield, water productivity and fruit quality of processing tomato under semi-arid Mediterranean climate conditions. Scientia Horticulturae, 2011; 129(4): 590-596.

[38] Romero-Trigueros C, Parra M, Bayona J M, Nortes P A, Alarcón J J, Nicolás E. Effect of deficit irrigation and reclaimed water on yield and quality of grapefruits at harvest and postharvest. LWT - Food Science and Technology, 2017; 85: 405-411.

[39] Calderon-Orellana A, Bambach N, Aburto F, Calderón M. Water deficit synchronizes berry color development in crimson seedless table grapes. American Journal of Enology and Viticulture, 2019; 70(1): 60-67.

[40] Veit-Köhler U, Krumbein A, Kosegarten H. Effect of different water supply on plant growth and fruit quality of Lycopersicon esculentum. Journal of Plant Nutrition and Soil Science, 1999; 162(6): 583-588.

[41] Guichard S, Gary C, Longuenesse J J, Leonardi C. Water fluxes and growth of greenhouse tomato fruits unser summer conditions. ActaHortic, 1999; 507(26): 223-230.

[42] Kumar P S, Singh Y, Nangare D D, Bhagat K, Kumar M, Taware P B, et al Influence of growth stage specific water stress on the yield, physico-chemical quality and functional characteristics of tomato grown in shallow basaltic soils. Scientia Horticulturae, 2015; 197: 261-271.

[43] Geng Y J, Chen L, Yang C, Jiao D Y, Zhang Y H, Cai Z Q. Dry-season deficit irrigation increases agricultural water use efficiency at the expense of yield and agronomic nutrient use efficiency of Sacha Inchi plants in a tropical humid monsoon area. Industrial Crops and Products, 2017; 109: $570-578$.

[44] Cui N, Du T, Kang S, Li F, Zhang J, Wang M, et al. Regulated deficit irrigation improved fruit quality and water use efficiency of pear-jujube trees. Agricultural Water Management, 2008; 95(4): 489-497.

[45] Hao S, Cao H, Wang H, Pan X. The physiological responses of tomato to water stress and re-water in different growth periods. Scientia Horticulturae, 2019; 249: 143-154.

[46] Chen J, Kang S, Du T, Qiu R, Guo P, Chen R. Quantitative response of greenhouse tomato yield and quality to water deficit at different growth stages. Agricultural Water Management, 2013; 129: 152-162. 